\title{
Biodegradable Ester-Amide Fabric Softeners
}

\author{
Shilpi Mishra and V.K. Tyagi ${ }^{*}$ \\ Department of Oil and Paint Technology \\ (Harcourt Butler Technological Institute, Kanpur-208002, INDIA)
}

Edited by T. Tamura, Lion Corp., and accepted January 30, 2006 (received for review December 13, 2005)

\begin{abstract}
Surfactants form a group of chemicals with considerable environmental importance due to their high volume consumption and widespread use as essential ingredients in most laundry and cleaning products. Since the major part of the biosphere is aerobic, so it is necessary that the surfactant must be biodegradable. Therefore, it is desirable to design new softener molecules, which will both perform in the washing machine or dryer and biodegrade better than current softeners once released to the waste streams. The present paper reviews the synthesis, properties and applications of biodegradable ester-amide fabric softeners.

Key words: biodegradation, cationic surfactant, quaternary ammonium salt, fabric softener, ester-amide quaternary, polyamine
\end{abstract}

\section{Introduction}

Fabric softening has been an important part of the home laundry routine for nearly 50 years. Softeners were introduced first in the U.S. market around 1955 and about 10 years later in Europe (1-3). This type of product is also widespread in Japan and is still expanding and growing worldwide (4). A softener is a chemical that softens the fabric and makes it more pleasing to the touch. The application of household fabric softeners during laundering has become a routine for American families (Baumert \& Crews,1996) (5). Fabric softeners can help to improve fabric hand and decrease unwanted static cling. Apart from this, fabric softeners are used in a variety of forms in consumer's applications. They are impart freshness or pleasant smell. Besides this, they control the static electricity that impairs the comfort handling and wearing clothes when ambient humidity is low. In addition to these qualities, softeners give drape and silkiness, improve abrasion resistance, increase tearing strength and reduce sewing thread breakage. designed to give a pleasant feel to garments, and to

Softeners are normally applied by the consumers after fabrics are laundered (6). The market of the fabric softeners is growing. This is mirrored in the projection of a $3-8 \%$ annual growth rate in various markets around the world (7) (Table 1).

The main ingredient in fabric softeners is a cationic surfactant. Cationic softeners were discovered in the early years of the 20th century but were not used by the

Table 1 World Fabric Softener Consumptions ${ }^{\mathrm{a}}$.

\begin{tabular}{|l|c|c|c|c|}
\hline Region/Year & $\mathbf{1 9 9 5}$ & $\mathbf{2 0 0 0}$ & $\mathbf{2 0 0 5}$ & Growth $^{\mathbf{b}} \mathbf{( \% )}$ \\
\hline Europe & 115 & 130 & 140 & 2.5 \\
\hline United States & 72 & 86 & 104 & 3.5 \\
\hline Mexico & 7 & 10 & 15 & 7 \\
\hline South America & 17 & 23 & 31 & 6 \\
\hline Asia & 50 & $50-75$ & $50-100$ & $0-8$ \\
\hline Total & 261 & $300+$ & $350+$ & 4 \\
\hline
\end{tabular}

\footnotetext{
*Correspondence to: V.K. TYAgI, Department of Oil and Paint Technology, Harcourt Butler Technological Institute, Kanpur- 208002, INDIA
}

E-mail: vinod_tyagi1960@yahoo.co.in,shilpy_19@yahoo.co.in 
textile industry until the late 1930's (DuBrow \& Linfield, 1957) (8). They become technically important after Domagk discovered their bacteriostatic properties, their use as germicides and fungicides in cosmetic and antiseptic preparations (9).

Cationic surfactants are currently used as softener as well as for several other industrial applications. Cationic fatty materials can maintain or restore the original feel of fabrics. As a result, it was not long before domestic products appeared in the market (10-15). Since the 1940's, fabric treatment with cationic softeners has gained worldwide acceptance in the textile-finishing and textile-maintenance areas.

The first produced household fabric softener in the U.S. in the 1950s was based on di (hydrogenated tallow) dimethyl ammonium chloride, which is one of the sulfated quaternary ammonium compounds (Egan, 1978) (2). They are excellent lubricants and powerful anti-static agents (Puchta, 1984, Ward, 1957) $(1,16)$. There are three main types of quaternary ammonium compounds used in the formulation of household fabric softeners: dialkyldimethyl ammonium compounds, diamido alkoxylated ammonium compounds, and imidazolinium compounds (Egan, 1978; Williams, 1982) $(2,17)$.

During the nineteen's century quaternary ammonium salts containing ester groups have replaced traditional cationic surfactants in fabric softeners. These ester groups are commonly called as "esterquat", which is basically the class of surface-active quaternary ammonium compounds having the general formula $\mathrm{R}_{4} \mathrm{~N}^{+} \mathrm{X}^{-}$ (18). Within recent years, environmental concerns have become one of the main driving forces for the development of new fabric softening compositions with faster biodegradation, preferably two or three times faster than DHTDMAC(dehydrogenated tallow dimethyl ammonium chloride) (19). Ester-amide quats (Fig. 1) are prepared as alternative to diesterquats (20). As the consequence of the specific structure, quaternary ammonium salts containing ester-amide linkages have rapid and complete biodegradability along with better softening results (21).

\section{Mechanism of Fabric Softeners}

The softeners consists of two distinct parts: hydrophobic and hydrophilic (Ward, 1957) (1). The hydrophobic (or fatty) part is water hating, and does not mix with water. The hydrophilic part is water loving, resulting in compounds dispersing in water. When the surfactant is floated on the surface of the liquid, it lowers the surface tension and ionizes to create positive ions containing the hydrophobic groups. The hydrophobic part has a positive electrical charge, while the hydrophilic part is negatively charged.

The fabric softeners are called cationic because the positively charged hydrophilic parts are predominant in the rinse water when cationic softeners are added. Most fabrics are negatively charged, so all the cationics will be picked up by the fabrics and be retained on the fabric during the laundering process when fabric softeners are applied. The hydrophobic part of a fatty hydrocarbon is the agent that causes cationic softeners to lubricate the fibers in a fabric (McNally \& McCord, 1960) (22).

\section{Synthesis of Ester-Amide Quaternaries}

Conventionally the diesterquats are derived from alkanolamines and fatty acid followed by reaction with an alkylating agent to the corresponding quaternary (23). The reaction scheme for the preparation of the diester of bis-2 hydroxyethylmethyl ammonium chloride from methyldiethnolamine and fatty acid is given in Fig. 2

In order to prepare the fabric softener with better biodegradability, esteramide quats (Fig. 1) have been prepared as the best alternative of diester quats. Generally the synthesis of esteramide quaternary is carried out with primary or secondary alkanolamines (24), which may include heterocycles that are reacted with fatty acids. The hydroxyl group will form an ester function and the primary or secondary amine will react to an amide followed by $\mathrm{N}$-alkylation with the suitable alkylating agent like dimethyl sulphate, methyl chloride etc.

Lagarman (1993) (25) developed the quaternary

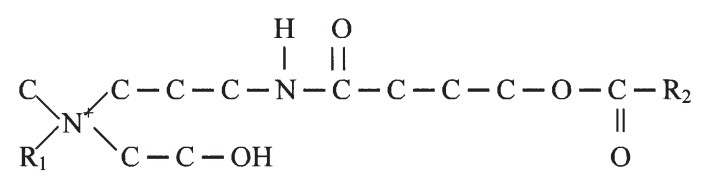

$\mathrm{Cl}^{-}$

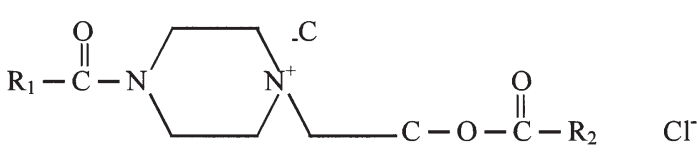

Fig. 1 Esteramide Quats. 

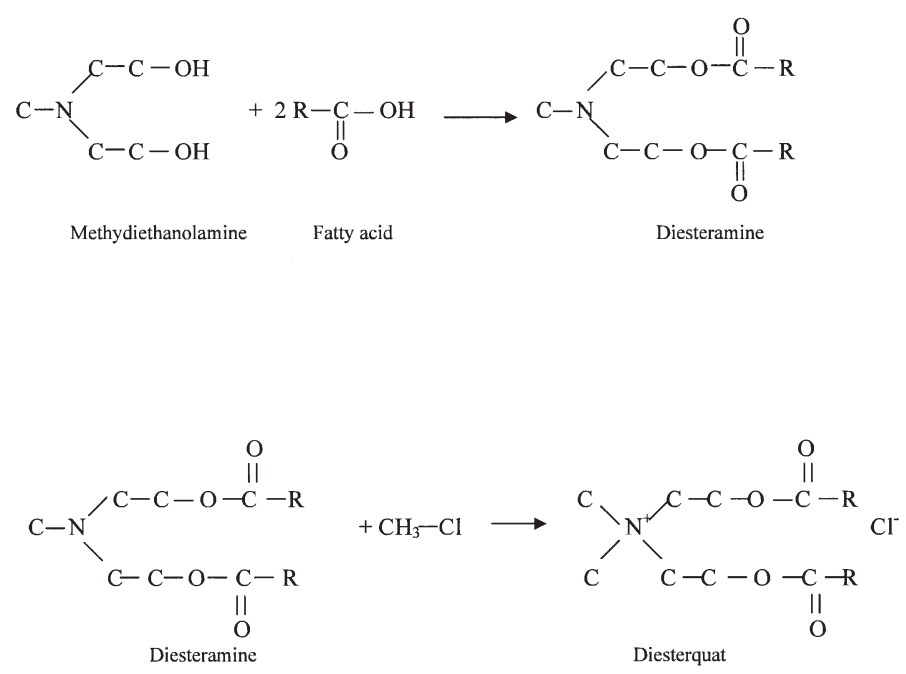

Fig. 2 Preparation of Diesterquat.

ammonium compounds containing amide groups, quaternized derivatives of amides of ester group-containing polyamines, e.g., $\mathrm{HOCH}_{2} \mathrm{CH}_{2} \mathrm{~N}^{+} \mathrm{MeR}\left(\mathrm{CH}_{2}\right)_{3} \mathrm{NHCO}-$ $\left(\mathrm{CH}_{2}\right)_{3} \mathrm{OCOR}^{1} \mathrm{MeSO}_{4}^{-} \quad(\mathrm{R}=$ hydrogenated tallow alkyl; $\mathrm{R}^{1}=\mathrm{C}_{17}$ alkyl) show good hydrolysis resistance and biodegradability and are useful as softeners and antistatic agents for fabrics, hair conditioners, clay modifiers, etc.

In 1994 Lagerman and his coworkers manufactured the biodegradable ester-amide quaternaries by the reaction of hydroxyethyl piperazine with fatty acids and the adduct (ester-amide) is then quaternized by suitable alkylating agents (26-28) as shown in the following Scheme 1.

In an another synthesis Lagarman and his cowork- ers(25) synthesized the biodegradable ester-amide fabric softener by the reaction of fatty diamine such as tallow diamine with a lactone like butyrolactone, the reaction of amines with lactones is well known(29), resulting in an amine-amino alcohol that still has two reactive functional groups, the amine and the alcohol. This material can be ethoxylated, and then esterified to produce the amido-amino-ester, which is quaternized with various quaternizing agents to produce the product.

An attractive feature of this scheme is that one fatty group can be changed independently of the other, giving unsymmetrical molecules and many possibilities to adjust the properties.

With an appropriate choice of long chain alkyl

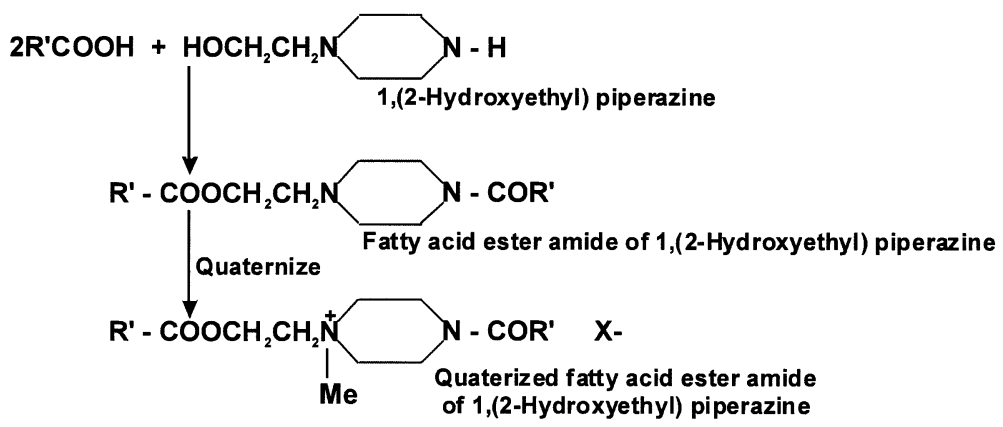

[1]

1a $R^{\prime}=$ Myristyl

b $\mathbf{R}^{\prime}=$ Stearyl

c $\mathbf{R}^{\prime}=$ Oleyl

d $\mathbf{R}^{\prime}=$ Hard Tallow
$\mathrm{X}=$ Chloride

$\mathrm{X}=$ Chloride

$X=$ Methyl Sulfate

$X=$ Methyl Sulfate

Scheme 1 
groups ( $\mathrm{R}$ and $\mathrm{R}$ ') these compounds give proper softening and at the same time much better biodegradation characteristics than conventional softeners (30).

Pi subirana and coworkers (31) prepared the esteramide quaternaries by partial esterification of an aliphatic or aromatic di and/or tricarboxylic acid such as citric acid or dodecanedioic acid with an aliphatic alcohol.(e.g. $\mathrm{C}_{16-18}$ tallow alcohols), then esterified or amidated the product with an alkanolamine or a polyamine and quaternization with an alkylating agent (i.e. dimethyl sulphate).

Toney and Friedli (32) synthesized the biodegradable quaternary amido-aminoester by hydrogenation of (2cyanoethyl)(2-hydroxyethyl)methylamine to the corresponding diamine, and then amidated the product with a mixture of stearic acid, palmitic acid, and eicosanoic acid followed by the quaternization. The obtained quaternized ester-amide is used as a biodegradable fabric softener, which exhibit useful fabric softening and static reduction properties as well as biodegradability.

Inoue (33) investigated the composition of esteramide compounds of $\mathrm{N}$-alkanolalkylene polyamines, used as a fabric softening and antistatic agents. These antistatic and fabric softening compounds was obtained from mixture of N-methyl -N-(hydrogenated tallow fatty acid esterified hydroxyethyl)-N-(hydrogenated tallow fatty acid amidated aminopropyl) amine, $\mathrm{HCl}$ salt 5, hydrogenated tallow fatty acid 1, a 50:25:10:15 mix- tures of di-Et phthalate, benzyl salicylate, benzyl acetate and citronellyl acetate, 0.1 and a perfume $0.03 \%$.

According to Kato et al. (34) ester-amide was synthesized by the reaction of amino alcohol with amino acids or their derivatives to give amidoamines, optionally treated with alkylene oxides to give the compound, which upon the reaction with fatty acids give diester amidoamines. These ester-amide quaternaries possess excellent biodegradability and good fabric softening applications.

Bonastre et al. (35) gave the manufacturing and use of new amido-ester quats. They were manufactured by hydrolyzing, esterifying with fatty acids and quaternizing the hydrolyzed linear products derived from $\mathrm{C}_{12-18}$ fatty acids. They are dispersible in cold water and are chemically more stable then ester quats with two ester groups.

Nakakawa and Yokoi (36) produced the nonirritant cleansing compositions containing amide sulfate estertype surfactants. The cleansing compositions e.g. shampoos, skin cleaners, dentifrices, dish washing and laundry detergents, contain amide-sulfate ester type surfactants that comprises of dodecanoic acid diethanolamide sulfate ester $\mathrm{Na}$ salt, dodecanoic acid diehanolamide, $\mathrm{Na}$ laurate, dodecanamide polyoxyethylene ether acetate $\mathrm{Na}$ salt, etc was mild to the skin and showed good foaming properties and cleansing effect.

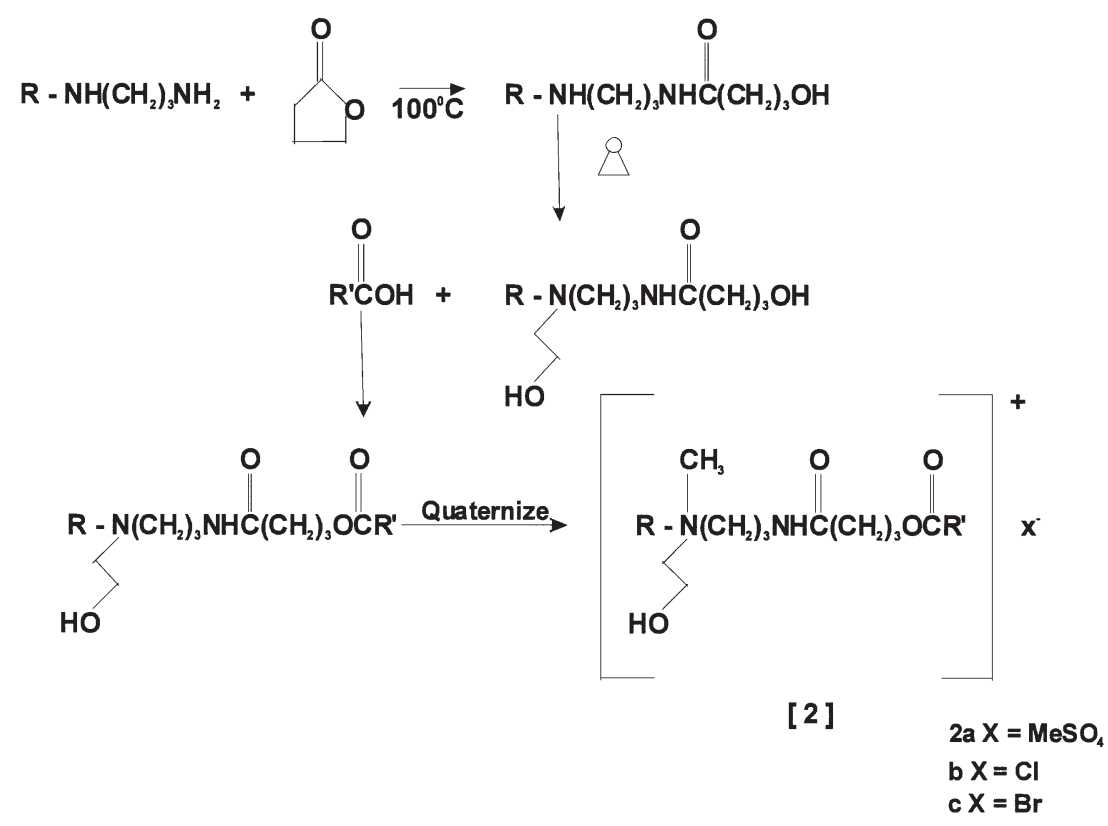

Scheme 2 
Lassila and Rodney (37) prepared alkylated amino alkyl piperazine as surfactants in water based compositions, .alkylated amino alkyl piperazine compounds of the structure as shown below in Fig. 3, where one of $\mathrm{R}^{1} \& \mathrm{R}^{2}=\mathrm{a} \mathrm{C}_{5-14}$ alkyl or cyclo alkyl group and other is $\mathrm{H}$, or both $\mathrm{R}^{\prime}=\mathrm{C}_{5-8}$ alkyl groups and $\mathrm{n}=2$ or 3 , are synthesized by reductive alkylation of parent amino alkyl piperazine with aldehydes or ketones.

Many new diesterquats and amidoester quats were synthesized and tested for biodegradation and softening. Friedli and coworkers (38) had synthesized these quats by taking methyldiethanolamine, 3-methoxylpropylamine, diethanolaminopropylamine, aminoethylethanolamine, dimethylethanolamine and diethanolamine as a raw material either "as it is" or after alkoxylation, with tallow fatty acid and further converted into dialkyl quats. The diesterquat from diethanolisopropanolamine was by far the best of the esterquats synthesized in overall biodegradation, softening, and cost/ease of manufacture. It appears that two ester groups are needed for ready biodegradation as opposed to an amide-ester combination. Increasing unsaturation of the alkyl chains within a molecule increases its rate of biodegradation slightly.

\section{Properties of Ester-Amide Quaternaries}

Various scientists have studied these performance properties. Ester-amide quats exhibit excellent biodegradability, wetting, high hydrolytic stability and concentration ability etc(39). The combined properties of quaternary ammonium compounds including germicidal activity, detergent action, low toxicity, high solubility, stability and noncorrosiveness facilitate their application as disinfectants and sanitizing agents (40, 41).

\subsection{Biodegradability}

Biodegradation is the most important mechanism for the irreversible removal of chemicals from the aquatic and terrestrial environments. It may be defined as the destruction of chemical compounds by the biological action of living organisms. The environmental proper-

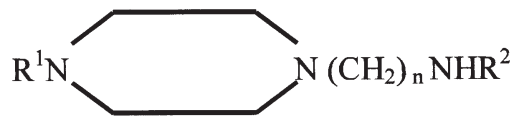

Fig. 3 Alkylated Aminoalkyl Piperazine. ties of esterquats have been studied extensively during the last few years. The diesterquats (conventional form of esteramide quats) that are used in large volumes today as actives in fabric softeners have been subject to very comprehensive studies. In general terms, it can be stated that the ester-amide bonds in these materials may undergo abiotic degradation at ambient conditions, which facilitates further biodegradation of the fragments. Fakhrouian 2003 (42) gave a review on the biodegradability of surfactants in waste water.

An excellent review of surfactant biodegradability (Swisher, 1987) (43) points out that biodegradability increases with increased linearity of the hydrophobic group and is reduced, for isomeric materials by branching in that group, particularly by terminal quaternary carbon branching. Pyridinium compounds biodegrade significantly more slowly than corresponding trimethylammonium compounds, while ester-amide quaternaries show rapid and complete biodegradation, because esteramide linkages are readily attacked by microorganisms, and the cleavage of these linkages results in smaller molecules that are easily biodegraded.

\section{$4 \cdot 2$ Softening}

Without doubt, softening depends on alkyl chain length and for best softening, two alkyl chains are preferred (13). No good mechanical method has yet been devised for the quantitative measurement of softness. As a result, the Ashland laboratories use a panel "feel" test in their evaluations and rates the softeners in the order of panel softening preference and not in percentage of effectiveness. Ester-amide quaternaries show excellent soften property as well as useful in cosmetic and pharmaceuticals formulation in laundry detergents (Inoue, 1999; Toney and Friedli 1998; Kato and coworkers 1999 \& 2000) (32-34,44).

The performances like biodegradability and fabric softening changes dramatically with structures as shown in given Table 2 (19). Table shows a comparison of the various performance criteria to the industry standard DHTDMAC.

According to the Table 2 the $\mathrm{C}-14$ version of the piperazine structure [1a] biodegrades excellently, but softening is unacceptable. Hard tallow and stearyl are best for softening, with the stearyl biodegrading somewhat better [ $1 \mathrm{~b}$ vs. $1 \mathrm{f}$ and $2 \mathrm{a}$ vs. $2 \mathrm{~d}$ ]. This is one of the few structures to match DHTDMAC in softening. 
Table 2 Performance ${ }^{\mathrm{a}}$.

\begin{tabular}{|c|c|c|c|}
\hline Structure & Biodegradation & Softening & $\begin{array}{c}\text { Formulation } \\
\text { Stability }\end{array}$ \\
\hline DHTDMAC & $19 \%$ & Excellent & Fair \\
\hline 1a & 72 & Poor & Good \\
\hline b & 47 & Good & Fair \\
\hline c & 13 & Good & Good \\
\hline d & - & Poor & Excellent \\
\hline e & - & Good & Poor \\
\hline f & 40 & Good & Fair \\
\hline $2 a$ & 43 & Excellent & Poor \\
\hline b & 14 & Excellent & Good \\
\hline c & 21 & Excellent & Fair \\
\hline d & 22 & Excellent & Fair \\
\hline E & 33 & Excellent & Excellent \\
\hline
\end{tabular}

a percentage of theory obtained in $20 \mathrm{~d}$ when tested at $1 \mathrm{ppm}$. DHTDMAC, di hydrogenated tallow dimethyl ammonium chloride.

\subsection{Rewetting}

The ease with which a surface can be wetted by water or by other liquid is an important property from many considerations, including detergency, waterproofing, oil proofing, dying, dispersion of pigments and water absorption. A requirement of a wettings agent is evidently to reduce both the surface tension of liquid and interfacial tension against the solid (45).

Rewetting properties are important as they give an indication of the absorbency characteristics of fabric after treatment with an ester-amide softener. Water absorbency is important because too much fabric softener can water proof cloth. A general rule for any method of application is the more softener on the fabric, the poorer the water absorbency will be. Also, as softeners increases absorbency decreases $(2,46)$.

\subsection{Static Control}

Static control has become a very important attribute for ester-amide fabric softeners. The increased use of synthetic fibers has made the consumer more aware of the advantage of using fiber softeners to eliminate static cling. Fabric softeners act as anti-static agents by enabling synthetic fibers to retain sufficient moisture to dissipate static charges. After the application of fabric softeners on synthetic fibers, the lubricating film absorbs moisture from the air, which provides a way for discharging static electricity.

Whal and coworkers gave the concentrated biodegradable fabric softener compositions, which form stable aqueous concentrations containing $\geq 13 \%$ softener and are useful in the rinse cycle during laundering (30).

\subsection{Dispersibility}

Ester-amide quaternaries show good dispersing ability as reported by various scientist (Pi subirana et al. and Jeong, Gug- In et al.) $(31,47)$. They function in a manner similar to emulsifying agents. The difference is that solid particulate matter, rather than insoluble oils, is dispersed. The nature of the lipophilic part of the surfactant molecule must be such that it adsorb onto the particle's surface. Surfactant molecules must be matched with their intended use (31).

\subsection{Mildness}

Many studies showed that the usage of fabric softeners has no adverse effects on the skin (Bouchier-Hays, 1988; Jenkins \& Batham, 1983; Pierard et al. 1994; Rodriguez et al. 1994) (48-51). For example, Rodriguez, et al. 1994 conducted a series of studies to evaluate the effects of liquid fabric softeners on human skin. These studies included contact sensitization and contact irritation tests of softener formulations and softener treated fabrics, and extended family usage tests for a liquid fabric softener. The authors investigated that ester-amide quaternaries are mild to skin, their study results showed that softeners are not allergy sensitizers or irritating to the skin. Continuous home usage and wearing of softener-treated fabrics had no adverse effect on the skin.

\section{Applications of Ester-Amide Quaternaries}

The aspect of fabric softening has not been as important in the USA as in Europe, due to the use of relatively large agitator-type washing machines with shorter washing times, and also because of the more extensive use of laundry dryers and the much higher proportion of synthetic fibers. Ester-amide quaternaries are successfully used as a rinse cycle softeners.

Williams (17) reported that rinse cycle softeners were the most popular and the most effective way to soften the fabrics. Rinse cycle softeners are aqueous disper- 
sions of the cationic chemicals and contain $5-7 \%$ total solids for a concentrated "blue" fabric softener and 3$4 \%$ for a regular "pink" fabric softener (52). This type of fabric softeners is added to the laundry during the last rinse cycle, i.e., at a when soil and detergent residues have been almost completely removed. This is important because cationic ingredients of fabric softeners would be rendered ineffective by formation of neutral salts with the anionic surfactants from the laundry detergents.

Friedli et al. (38) prepared the novel new ester quaternaries for improved performance benefits as rinse cycle fabric softeners. The viscosity of rinse cycle softeners also varies with fatty alkyl composition. The longer the alkyl chain and higher the degree of saturation the higher the viscosity of the aqueous dispersion.

Quaternary ammonium salts (ester-amide quaternaries) are extremely important fatty acid derivatives. The quat's cationic charge is permanent, being maintained at all pHs. Ester-amide quaternaries exhibit the multiple uses like: fabric softening agent, hair conditioners, antistatic agent and germicidal agent, including these esteramide quats are useful in cosmetic, pharmaceutical formulation and in laundry detergents. They are also used as clay modifiers. Okutsu et al. prepared the amidoester used in detergent compositions and skin preparations. Ester-amide quaternaries impart fluffiness and antistatic properties to the fabrics. They effect more rapid drying because water is more readily released from the laundry. They also facilitate ironing (53).

In addition to imparting softness, quaternized derivatives of amides of ester group containing polyamines, show good hydrolysis resistance and biodegradability, reduce the static charge on synthetic fabrics and inhibit the growth of bacteria. Quats are therefore used as antibacterial agent. The behaviors of the synthesized cationic surfactants at the interface play a vital role in their antibacterial activity. The surface and thermodynamic properties of these surfactants showed a tendency towards adsorption at the interfaces, which facilitate their role of adsorption at the bacterial cell membrane. The alkylated amino alkyl piperazine compounds are used as effective surfactants in water based coating ink, adhesive fountain solution, agricultural compounds and photo resistant developing \& electronics cleaning compositions because of their excellent surfactant properties such as reduction in dynamic \& equal surface tension and the ability to control foam. An aquous solution of<smiles>[R]C(=O)OCC[N+](C)(C)CCOC([R])=O</smiles>

$\mathrm{R}=$ Palmitoyl, stearoyl<smiles>[R]C(=O)OCC[N+](C)(CCO)CCOC([R])=O</smiles>

$\mathrm{R}=$ Palmitoyl, stearoyl

Fig. 4 Esterquats Developed for Use in Hair Conditioners.

the alkylated amino alkyl piperazine demonstrates a dynamic surface tension of $<45$ dyne/c.m. at a concentration of $<5 \mathrm{wt} \%$ in water at $23^{\circ} \mathrm{C}$ and $1 \mathrm{bubble} / \mathrm{sec}-$ ond according to the max. bubble pressure method(37).

Cationics containing two $\mathrm{C}_{18}$ fatty tails attached to the nitrogen impart very soft, fluffy hand to textile product softeners (54). A lot of research had been conducted on the effects of softeners on fabric properties, such as the appearance properties (i.e., wrinkle recovery, pilling, and whiteness) by (Baumert \& Crews, 1996; Chiweshe \& Crews, 2000; Crutcher, et al. 1992; Simpson \& Silvernale, 1976; Wilson, 1987) (5, 55-58).

Quaternary ammonium compounds are the key raw materials for hair conditioners. Recently, esterquats have been commercially for hair care applications. These products are derived from alkanolamines and

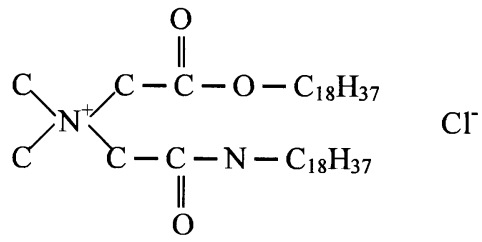<smiles>CCCCCCCCCCCCCCCCCCCCCCCCCCCCCCCCCCCCCCCCCCCC</smiles>

Fig. 5 Amide Esterquats. 
preferably fatty acids of vegetable origin (Fig. 4).

Hair cosmetic compositions containing amide esterquats of the following structures give smooth touch to hair and prevent tangling $(59,60)$.

\section{Cost Considerations}

Cost considerations, of course, are important when formulating a finished fabric softeners . A few guidelines can aid in selecting the right product at the right price.

In many cases, the contribution of the cationic softener to the final product cost is more important than the price of the cationic. The contribution of the softener price to a liquid finish product cost in dollars per gallon is calculated as follows (52).

Softener cost (\$/ \#) x\% softener in product $x 8.3$

\section{Concentration of the softener (\%)}

\section{$=$ Cost of product due to softener}

\section{Conclusion}

The household fabric softeners have been used in the United States for more than 50 years. Although some studies examined the effect of fabric softeners in environment. It is always been a interesting topic to discover a novel type of fabric softener which shows rapid and complete biodegradability along with fabric softening.

The ester-amide quaternaries shall have certain advantages over all the conventional and old generation cationic fabric softeners such as easier preparation, cheaper raw materials, excellent biodegradability, OECD approval, and ease of formulations etc. They will also be ecofriendly because of their excellent biodegradability. It has been developed to overcome some of the drawbacks of the currently used quaternary ammonium surfactants.

\section{References}

1. H.L. WARD, Textile Softeners For Home Laundering, Journal of Home Economics, Vol. 49, 122-123 (1957).

2. R.R. EGAN, Cationic Surface Active Agents As Fabric Softeners, J. Am. Oil Chem. Soc., Vol. 55, 118-121 (1978).

3. R. MULLIN, Soaps And Detergents, Chemical Week, Vol. 150, 24 (1992)

4. K.-Y. LAI, Liquid Detergents (K.-Y. LAI ed.), Surfactant Science Series, Vol. 67, Marcel Dekker, New York, p. 434 (1996).
5. K.J. BAUMERT and P.C. CREWS, Influence of Household Fabric Softeners on Properties of Selected Woven Fabrics, Textile Chemist And Colorist, Vol. 28, 36 (1996).

6. D.R. CHARLES, Tomasino Chemistry \& Technology of Fabric Preparation \& Finishing, Vol. 136 (1992).

7. R. TYAGI and R.K. KHANNA, Global Trends in Cationic Fabric Softeners, J. Oil Tech. Ass. India, Vol. 32, 71-75 (2000).

8. P.L. DUBROW and W.M. LINFIELD, Cationic Textile Softeners For Home Fabric Softeners, Soap And Chemical Specialties, Vol. 33, 89-97 (1957).

9. G. DOMAGK, Dtsch. Med. Wochenscher, Vol. 21, 829 (1935).

10. G.K. HUGHES and S.D. KOCH, Soap/ Cosmetic/ Chemical Specialties, Vol. 42, 109 (1965).

11. W.P. EVANS, Chemistry And Industry, Vol. 27, 893 (1969).

12. FOLEY, Recent Developments In Fabric Softener Technology, $J$. Soap/ Cosmetic/ Chemical Specialties, Vol. 55, 25 (1978).

13. J.G. FULLER and J.A. ACKERMAN, How To Choose Cationics For Fabric Softeners, J. Am. Oil Chem. Soc., Vol. 60, 172 (1983).

14. J.A. ACKERMAN, How To Choose Cationics For Fabric Softeners, J. Am. Oil Chem. Soc., Vol. 60, 1166 (1983).

15. B. MILWIDSKY, Happi, Vol. 25, 40 (1987).

16. R. PUCHTA, Cationic Surfactants In Laundry Detergents and Laundry After Treatment Aids, J. Am. Oil Chem. Soc., Vol. 61, 367 (1984).

17. J.A. WILliamS, How To Choose Cationics For Fabric Softeners, Soap/ Cosmetics/Chemical Specialties, Vol. 59, 28-32 (1982).

18. G. KRUGER, D. BOLTERSDORF and K. OVERKEMPE, Novel Surfactants, Preparations, Applications And Biodegradability (K. HOLMBERG, ed.), Surfactant Science Series, Vol. 114, Marcel Dekker, New York, p. 116 (2003).

19. R. LAGERMAN, S. CLANCY, D. TANNER, N. JOHNSTON, B. CALLIAN and F. FRIEDLI, Synthesis And Performance of Ester Quaternary Biodegradable Softeners, J. Am. Oil Chem. Soc., Vol. 71, 97 (1994).

20. G. KRUGER, D. BOLTERSDORF and K. OVERKEMPE, Novel Surfactants, Preparations, Applications And Biodegradability (K. HOLMBERG, ed.), Surfactant Science Series, Vol. 114, Marcel Dekker, New York, p. 122 (2003).

21. R.K. LAGERMAN, S.F. CLANCY, D.A. TANNER, N.L. JOHNSTON, B.I. CALLION and F.E. FRIEDLI, Synthesis, Performance, and Biodegradation of New Biodegradable Softeners, Inform, Vol. 3, 528 (1992).

22. J.P. MCNALLY and F.A. MCCORD, Cotton Quality Study V: Resistance To Abrasion, Textile Research Journal, Vol. 30, 715 (1960).

23. J. BIGORRA, F. CUADRADO, M. HUMBERT, J. POMARES and A. TRIUS, PCT Int. Appl. WO 9101295 to Henkel K.G.a.A., Pulcra S.A. (1991)

24. J. INOKOSHI, T. KATOH, Y. TOSHIMA, M. YAMAMURA and M.J. BERMIJO, $4^{\text {th }}$ World Surfactant Congress, Barcelona Proceedings, Vol. 2, 334 (1996).

25. R.K. LAGERMAN, Quaternary Ammonium Compounds Con- 
taining Amide Groups, Especially For Use As Fabric Softeners, (Sherex Chemical Co., Inc.) Eur. Pat. Appl. Ep 517, 954 16DEC1992, C. A., Vol. 118, 171519k (1993).

26. R. ERNST., U.S. PAT., 3,165.554 (1965).

27. H. RATO, T. MOURI and T. NISHIKAWA, U.S. PAT., 4,068,069 (1978).

28. H. RATO, T. MOURI and T. NISHIKAWA, U.S. PAT., 3,980,643 (1976).

29. S.R. BUC and E.P. WILLIAMS, U.S. PAT., 2,945, 863 (1960).

30. E.W. HOFFMAN, B.D. RAY, B.E. SCHMIDT, B.J. FRANCOIS, B.M. EUGENE, C. ALBERT, S.J. CORT, et al., PROCTER \& GAMBLE CO, C. A., Vol. 122, 268696m (1995).

31. R.P. SUBIRANA, N. BONASTRE, L.J. BIGORRA and B. FABRY, Surfactants Comprising Quaternized Ester-Amides of Polycarboxylic Acids, Pct Int. Appl, C. A., Vol. 126, 48618e (1997).

32. C.J. TONEY and F.D. FRIEDLI, Biodegradable Quaternary Amido Amino Ester Fabric Softeners, Sherex Chemical Co, Inc., USA, C. A., Vol. 128, 231877u (1998).

33. K. INOUE, Fabric Softening and Antistatic Agents, Jpn. Kokai Tokkyo Koho, C. A., Vol. 130, 313504a (1999).

34. T. KATO, N. UICHIRO, T. OSAMU and O.Y. SOTODANI, Quaternary Ammonium Compounds With Improved Biodegradability For Softening Agents, Jpn. Kokai Tokkyo Koho, C. A., Vol. 125, 332365u (1996).

35. G.N. BONASTRE, B. JOAQIN and P.S. RAFAEL, Manufacture and Use Of New Amide Ester Quats, Ger. Offen, C. A., Vol. 133, $32091 \mathrm{~m}$ (2000).

36. R. NAKAGAWA and K. YOKOI, Nonirritant Cleansing Compositions Containing Amide Sulfate Ester-Type Surfactants, Jpn. Kokai Tokkyo Koho, C. A., Vol. 130, 114769r (1999).

37. K.R. LASSILA, Alkylated Amino Alkyl Piperazine As Surfactants In Water Based Compositions, Air Products And Chemicals, Inc, USA., C. A., Vol. 134, 368616b (2001).

38. F.E. FRIEDLI, K. ROBERT, C.J. TONEY, P. OWEN, W. DAVE and D. MARKUS, Biodegradable Quaternary Amidoaminoester Fabric Softeners, J. Surfactants and Detergents, Vol. 4, 401 (2001).

39. P.M. LENOIR, S. JOHANNES, W.F. DELCOUR and K.M. MARINERS, Method For Producing Softener Compositions Comprising Quaternised Fatty Acid Esters And/Amides (Ester Quats) Having High Hydrolytic Stability And Concentration Ability, The Dow Chemical Comp. USA, C. A., Vol. 133, 283310b (2000).

40. M. BOIVIN, Perf. 34. Abstract- Compendex /Cited By Scopus, 65 (1995).

41. K.D. BRUNT and H.C. HILL, Biocides For The Oil Industry, (K.D. BRUNT and H.C. HILL, ed.), Vol. 201, Willey, New York (1987).

42. F. ZAHRA, Biodegradability of Surfactants, Tahqiq-IPizhuhishgah-I-Sanat-I-Naft, 12, 58-81, Nioc Research Institute of Petroleum Industry, C. A., Vol. 138, 77625h (2003).

43. M.J. ROSEN, Surfactant And Interfacial Phenomena, 3rd edn.,
Isbn, 471-478, John Willey \& Sons Inc., 31 (2004).

44. T. KATO, N. UICHIRO, O. YASUNORI and H. YOSHIO, Preparation of Biodegradable Amide- and/or Ester-Containing Amines As Softeners, Jpn. Kokai Tokkyo Koho, C. A., Vol. 131, 214010a (1999) .

45. W.G. CUTLER and R.C. DAVIS, Detergency Theory and Test Methods, Part I, (W.G. CUTLER and R.C. DAVIS, ed.), Surfactant Science Series, Vol. 5, Marcel Dekker, New York, pp. 7 (1972).

46. FABRIC SOFTENERS, CONSUMER REPORTS, Vol. 48 (1979).

47. G.I. JEONG, H.J. WOOK and Y. YOON, Method For Preparing of Cationic Surfactant and A Fabric Softeners Compositions, Lg-Household \& Health Care Ltd., S. Korea, C. A, Vol. 138, 273337e (2003).

48. B. HAYS, T. A. I., Do Fabric Conditions Cause Nappy Rash? Midwife, Health Visitor \& Community Nurse, Vol. 24, 276 (1988).

49. H.L. JENKINS and D.M. BATHAM, Fabric Conditions: Do They Cause Nappy Rash? Midwife, Health Visitor \& Community Nurse, Vol. 19, 464 (1983).

50. G.E. PIERARD, J.E. ARRESE, A. DOWLATI, P.A. DASKALEROS and C. RODRIGUEZ, Effects of Softened and Unsofteden Fabrics on Infant Skin, International Journal of Dermatology, Vol. 33, 138 (1994).

51. C. RODRIGUEZ, P.A. DASKALEROS, L.J. SAUERS, J.D. INNIS, R.D. LAURIE and H. TRONNIER, Effects of Fabric Softeners on The Skin, Dermatosen, Vol. 42, 58 (1994).

52. J.A. ACKERMAN, SHEREX CHEMICAL COMPANY, 5777 FRANTZ, ROAD PO BOX 646, DUBLIN, OH 43017, How To Choose Cationics For Fabric Softeners, J. Am. Oil Chem. Soc., Vol. 60, 1166 (1983).

53. M.K. SCHWITZER and A.VAN SALDERN, Fette Seifen Anstrichm, Vol. 70, 349 (1968).

54. D.S. LYLE, Performance of Textiles, New York, John Wiley \& Sons, Vol. 86, 454 (1977).

55. A. CHIWESHE and P.C. CREWS, Influence of Household Fabric Softeners and Laundry Enzymes on Pilling and Breaking Strength, Textile Chemist And Colorist \& American Dyestuff Reporter, Vol. 32, 41 (2000).

56. T. CRUTCHER, K.R. SMITH, J.E. BORLAND, J.D. SAUER and J.W. PERINE, Alkyldimethylamine Oxides As Synergistic Fabric Softeners, J. Am. Oil Chem. Soc., Vol. 69, 682 (1992).

57. H.N. SIMPSON and C. SILVERNALE, How Laundering with Fabric Softeners Affect Flame Retardant Cotton Fabrics, American Dyestuff Reporter, Vol. 65, 36-42 (1976).

58. P. WILSON, Bioredible Polymers, American Association of Textile Chemists and Colorists, Vol. 106, 346 (1987).

59. N. HORINISHI and K. YAHAGI, Jap. Pat., 07309,723 to Kao Corp. (1995).

60. N. HORINISHI and K. YAHAGI, Jap. Pat., 07309,724 to Kao Corp. (1995). 